\title{
The Role of Polarizabilities in the Fluorescence Behaviour of 4-cyano-N,N-dimethylaniline
}

\author{
Wolfram Baumann \\ Institut für Physikalische Chemie, Universität Mainz \\ Z. Naturforsch. 36a, 868-875 (1981); received June 22, 1981
}

The effect of an external electric field on the absorption and the double fluorescence of 4cyano-N,N-dimethylaniline can be understood, taking into account reaction field induced polarizability effects. If a TICT state conformation emits the a-fluorescence in dioxane, the permanent dipole moment in this state is only slightly larger than in the equilibrium ground state.

\section{Introduction}

Lippert et al. [1] have first reported that with 4cyano-N,N-dimethylaniline (dimethylaminobenzonitrile $\equiv D M A B N$ ) in polar solvents there are two fluorescence bands, called a- and b-fluorescence, but only the b-fluorescence in nonpolar solvents. He ascribed this effect to a solvent induced reversal of the two lowest excited singlet states having different dipole moments.

Later on other models have been proposed and discussed extensively in the literature [2-7]. Besides the level crossing model it seems now that there is only one other model remaining: The TICT model introduced by Krystyna Rotkiewicz, K. H. Grellmann, Z. R. Grabowski [7] and discussed in a series of papers [7-12], where this idea is shown to be applicable to a lot of molecules consisting of a donor and an acceptor subassembly. Also, results of theoretical investigations on such molecules have been shown to be consistent with the TICT model [11, 13-17]. The TICT model ascribes the two fluorescence bands to two rotational isomers with coplanar or twisted donor and acceptor subunits of these molecules. In some recent papers Rettig, Wermuth and Lippert [18-20] have shown that a combination of the level crossing model and the TICT model might account for all observed effects in this class of molecules.

Starting from the idea that the TICT state is expected to have a very much larger dipole moment than the primarily excited Franck-Condon (FC) state, the electrooptical investigations described in this paper have been performed. The comparison of

Reprint requests to Prof. Dr. W. Baumann, Institut für Physikalische Chemie der Universität, Jakob-Welder-Weg 26, D-6500 Mainz. the dipole moment of the excited $\mathrm{FC}$ state and the equilibrium excited state (equilibrated with respect to intramolecular as well as to intermolecular relaxations after excitation) then should give valuable insight into the nature of the excited state emitting the longwavelength a-fluorescence in polar sovents. On the other hand, from similar investigations on 4-(9-anthryl)-N,N-dimethylaniline and related molecules came the idea [21] that the polarizability of these molecules could stand for at least part of the observed effects. Also, Wermuth, Rettig and Lippert in their recent paper [19] found that the solvatochromism of $\mathrm{p}-\mathrm{N}, \mathrm{N}$-diethy aminobenzoic acid ethylester could be better described taking into account polarizabilities. So reaction field induced polarizability effects on the experimentally determined dipole moments of DMABN in solution will be considered in this paper, too.

\section{Theoretical and Experimental}

Experimental methods used to determine dipole moments in solutions in Franck-Condon and in equilibrated excited states are electrooptical absorption measurements (EOAM) and electrooptical emission measurements (EOEM). EOAM has been developed in a lot of papers by Labhart [22-24] and Liptay [25-30], whose most elaborated theoretical model has been taken for EOEM [31], too. In this way results from both methods are comparable on the basis of the same model. This model, founded on the work of Onsager [32] and Scholte [33] approximates the solute molecule as a polarizable point dipole situated in the center of a cavity, the shape and size of which may be approximated by the shape and size of the solute. In this paper the most simple spherical approximation is used,

0340-4811 / $81 / 0800-0868 \$ 01.00 / 0$. - Please order a reprint rather than making your own copy. 
where the cavity is approximated by a sphere of radius $a$. The theory developed in Ref. [4] is only valid if the life time of the molecules investigated by EOEM is much longer than all reorientation relaxation times in solution. This condition is fulfilled with DMABN, as is shown below.

With EOEM [31] the relative change of the fluorescence photon current density is measured, when an external electric field $E_{\mathrm{a}}$ is applied. It is measured as a function of the fluorescence wavenumber $\tilde{\nu}_{\mathrm{e}}$ and the angle between the external electric field and the polarization direction, given by an analyzing polarizer. Then the following quantities can be derived [31] from EOEM, if smaller contributions are neglected:

$$
\begin{aligned}
E^{\mathrm{e}} & =\beta^{2}\left[3\left(\boldsymbol{m}_{\mathrm{e}} \vec{\mu}_{\mathrm{a}}\right)^{2}-\mu_{\mathrm{a}}{ }^{2}\right], * \\
F^{\mathrm{e}} & =\beta \vec{\mu}_{\mathrm{a}} \Delta \mathrm{e} \vec{\mu}, \\
G^{\mathrm{e}} & =\beta\left(\boldsymbol{m}_{\mathrm{e}} \vec{\mu}_{\mathrm{a}}\right)\left(\boldsymbol{m}_{\mathrm{e}} \Delta \mathrm{e} \vec{\mu}\right), \\
H^{\mathrm{e}} & =(\Delta \mathrm{e} \mu)^{2}, \\
I^{\mathrm{e}} & =\left(\boldsymbol{m}_{\mathrm{e}} \Delta \mathrm{e}^{\mathrm{\mu}}\right)^{2},
\end{aligned}
$$

with $\beta=(k T)^{-1}$.

Quite similar with EOAM $[27,30]$ the relative change of the absorbance is measured, when an external electric field is applied. It is measured as a function of the absorption wavenumber $\tilde{\nu}_{\mathrm{a}}$ and the angle between the external electric field and the electric field vector of the linearly polarized light, defined by a polarizer. From these measurements the following quantities can be derived if smaller contributions are neglected:

$$
\begin{aligned}
E^{\mathrm{a}} & =\beta^{2}\left[3\left(\boldsymbol{m}_{\mathrm{a}} \vec{\mu}_{\mathrm{g}}\right)^{2}-\mu_{\mathrm{g}}{ }^{2}\right], \\
F^{\mathrm{a}} & =\beta \vec{\mu}_{\mathrm{g}} \Delta^{\mathrm{a}} \vec{\mu}, \\
G^{\mathrm{a}} & =\beta\left(\boldsymbol{m}_{\mathrm{a}} \vec{\mu}_{\mathrm{g}}\right)\left(\boldsymbol{m}_{\mathrm{a}} \Delta^{\mathrm{a}} \vec{\mu}\right), \\
H^{\mathrm{a}} & =\left(\Delta^{\mathrm{a}} \mu\right)^{2}, \\
I^{\mathrm{a}} & =\left(\boldsymbol{m}_{\mathrm{a}} \Delta^{\mathrm{a}} \vec{\mu}\right)^{2} .
\end{aligned}
$$

$\boldsymbol{m}_{\mathrm{e}}$ and $\boldsymbol{m}_{\mathrm{a}}$ are unit vectors in the direction of the transition moment involved with the emission and absorption process, respectively.

$$
\begin{aligned}
& \vec{\mu}_{\mathrm{g}}=\mathrm{f}_{\mathrm{e}}\left(1-\mathrm{f} \alpha_{\mathrm{g}}^{0}\right)^{-1} \vec{\mu}_{\mathrm{g}}^{0}, \\
& \vec{\mu}_{\mathrm{a}}=\mathrm{f}_{\mathrm{e}}\left(1-\mathrm{f} \alpha_{\mathrm{a}}^{0}\right)^{-1} \vec{\mu}_{\mathrm{a}}^{0},
\end{aligned}
$$

* Anm. d. Red.: Aus satztechnischen Gründen mußte der Vektor $\vec{\mu}$ mit Pfeil statt fett, kursiv gesetzt werden.

$$
\begin{aligned}
\Delta^{\mathrm{a}} \vec{\mu}= & \left(1-\mathbf{f}^{\prime} \alpha_{\mathrm{a}}^{0 \mathrm{FC}}\right)^{-1}\left(1-\mathrm{f} \alpha_{\mathrm{a}}^{0 \mathrm{FC}}\right)\left(1-\mathrm{f} \alpha_{\mathrm{g}}^{0}\right)^{-1} \\
& \cdot\left(1-\mathbf{f}^{\prime} \alpha_{\mathrm{g}}^{0}\right)\left(\vec{\mu}_{\mathrm{a}}^{\mathrm{FC}}-\vec{\mu}_{\mathrm{g}}\right), \\
\Delta^{\mathrm{e}} \vec{\mu}= & \left(1-\mathbf{f}^{\prime} \alpha_{\mathrm{g}}^{0 \mathrm{FC}}\right)^{-1}\left(1-\mathbf{f} \alpha_{\mathrm{g}}^{0 \mathrm{FC}}\right)\left(1-\mathrm{f} \alpha_{\mathrm{a}}^{0}\right)^{-1} \\
& \cdot\left(1-\mathbf{f}^{\prime} \alpha_{\mathrm{a}}^{0}\right)\left(\vec{\mu}_{\mathrm{a}}-\vec{\mu}_{\mathrm{g}}^{\mathrm{FC}}\right),
\end{aligned}
$$

where $\vec{\mu}_{\mathrm{g}}^{\mathrm{FC}}$ and $\vec{\mu}_{\mathrm{a}}^{\mathrm{FC}}$ are defined analogous to (11) and (12):

$$
\begin{aligned}
& \vec{\mu}_{\mathrm{g}}^{\mathrm{FC}}=\mathbf{f}_{\mathrm{e}}\left(1-\mathbf{f} \boldsymbol{\alpha}_{\mathrm{g}}^{0 \mathrm{FC}}\right)^{-1} \vec{\mu}_{\mathrm{g}}^{0 \mathrm{FC}}, \\
& \vec{\mu}_{\mathrm{a}}^{\mathrm{FC}}=\mathbf{f}_{\mathrm{e}}\left(1-\mathbf{f} \boldsymbol{\alpha}_{\mathrm{a}}^{0 \mathrm{FC}}\right)^{-1} \vec{\mu}_{\mathrm{a}}^{0 \mathrm{FC}} .
\end{aligned}
$$

In this paper the spherical approximation for the Onsager cavity is used, so

$$
\begin{aligned}
\mathbf{f}_{\mathrm{e}} & =\frac{3 \varepsilon}{2 \varepsilon+1} \cdot \mathbf{1}=f \cdot \mathbf{1}, \\
\mathbf{f} & =\frac{1}{4 \pi \varepsilon_{0}} \frac{2}{a^{3}} \frac{\varepsilon-1}{2 \varepsilon+1} \cdot \mathbf{1}=f \cdot \mathbf{1}, \\
\mathbf{f}^{\prime} & =\frac{1}{4 \pi \varepsilon_{0}} \frac{2}{a^{3}} \frac{n^{2}-1}{2 n^{2}+1} \cdot \mathbf{1}=f^{\prime} \cdot \mathbf{1}
\end{aligned}
$$

with $a$ being the radius of the sphere, $\varepsilon_{0}$ the permittivity of the vacuum, $\varepsilon$ the dielectric constant and $n$ the refractive number.

In nonpolar solvents $f$ equals $f^{\prime}$ and therefore (13) and (14) become very simple:

$$
\begin{aligned}
& \Delta^{\mathrm{a}} \vec{\mu}=\vec{\mu}_{\mathrm{a}}^{\mathrm{FC}}-\vec{\mu}_{\mathrm{g}}, \\
& \Delta^{\mathrm{e}} \vec{\mu}=\vec{\mu}_{\mathrm{a}}-\vec{\mu}_{\mathrm{g}}^{\mathrm{FC}} .
\end{aligned}
$$

$\vec{\mu}^{0}$ and $\alpha^{0}$ denote dipole moments and polarizability tensors of the free molecule.

$\vec{\mu}_{\mathrm{g}}^{0}, \boldsymbol{\alpha}_{\mathrm{g}}^{0}$ and $\vec{\mu}_{\mathrm{a}}^{0}, \boldsymbol{\alpha}_{\mathrm{a}}^{0}$ are dipole moments and polarizabilities of the equilibrium ground state and of the equilibrated excited state of the molecule under consideration, $\vec{\mu}_{\mathrm{a}}^{0 \mathrm{FC}}$ and $\boldsymbol{\alpha}_{\mathrm{a}}^{0 \mathrm{FC}}$ are dipole moment and polarizability of the Franck-Condon (FC-) excited state, reached by the absorption process and $\vec{\mu}_{\mathrm{g}}^{0 \mathrm{FC}}$ and $\alpha_{\mathrm{g}}^{0 \mathrm{FC}}$ those of the FC ground state reached by the emission process.

The experimental setup used in both methods is described in [34] and [35].

\section{Experimental Results}

\section{III.1. Results of Electrooptical Emission Measure- ments on the a-fluorescence of DMABN}

EOEM have been performed on DMABN in dioxane at $298 \mathrm{~K}$. The solutions could not be deairated in the measuring cell used. Dioxane has been 
Table 1. Results of EOEM on solutions of DMABN in dioxane. $\Delta \tilde{v}_{\mathrm{e}}$ shows the spectral range used for the determination of $E \mathrm{e}$ to $G \mathrm{e}, \delta \tilde{v}_{\mathrm{e}}$ is the spectral bandwidth of the fluorometer used for EOEM. Excitation bandpass has been $(34-37) \cdot 10^{5} \mathrm{~m}^{-1}$.

\begin{tabular}{lc}
\hline & a-fluorescence \\
\hline$E \mathrm{e} / 10^{-20} \mathrm{~m}^{2} \mathrm{~V}^{-2}$ & $51500 \pm 300$ \\
$F \mathrm{e} / 10^{-40} \mathrm{CV}^{-1} \mathrm{~m}^{2}$ & $10100 \pm 400$ \\
$G \mathrm{e} / 10^{-40} \mathrm{CV}^{-1} \mathrm{~m}^{2}$ & $10100 \pm 400$ \\
$\Delta \tilde{v}_{\mathrm{e}} / 10^{5} \mathrm{~m}^{-1}$ & $20.4 \pm 24.4$ \\
$\delta \tilde{v}_{\mathrm{e}} / 10^{5} \mathrm{~m}^{-1}$ & 0.6 \\
\hline
\end{tabular}

used as a pseudopolar solvent that withstands very well breakdown at high electric fields.

In order to assure that all orientational relaxations have come to an end before emission takes place, the fluorescence decay time $\tau_{\mathrm{f}}$ has been measured for DMABN in those nondeairated dioxane solutions used for EOEM. Excitation at $(34-37)$ $\cdot 10^{5} \mathrm{~m}^{-1}$ and monitoring the a-fluorescence at wavenumbers smaller than $24.0 \cdot 10^{5} \mathrm{~m}^{-1}$, resulted in $\tau_{\mathrm{f}}=(3.2 \pm 0.1) \mathrm{ns}$.

This decay time is much longer than the solvent and solute reorientational relaxation times in dioxane. So (1) to (5) apply for the evaluation of the molecular properties from EOEM.

The results of EOEM on DMABN are shown in Table 1. Errors shown are single standard deviations as derived from a regression analysis.

\section{III.2. Determination of Dipole Moments from the a-Fluorescence of DMABN in Dioxane}

With the values from Table 1 using (1)-(3) the dipole terms in Table 2 are calculated.

Table 2 shows that from the a-fluorescence one finds

$$
\vec{\mu}_{\mathrm{a}} \Delta \mathrm{e} \vec{\mu}=\left(\boldsymbol{m}_{\mathrm{e}} \vec{\mu}_{\mathrm{a}}\right)\left(\boldsymbol{m}_{\mathrm{e}} \Delta \mathrm{e} \vec{\mu}\right) .
$$

Table 2. Dipole moments of DMABN as determined by EOEM from the a-fluorescence. The value of $\mu_{\mathbf{g}}^{\text {FC }}$ is put into brackets, because in pseudopolar dioxane Eq. (21) is not valid exactly.

\begin{tabular}{lc}
\hline & a-fluorescence \\
\hline$\left[3\left(m_{\mathrm{e}} \vec{\mu}_{\mathrm{a}}\right)^{2}-\mu_{\mathrm{a}}^{2}\right] / 10^{-60} \mathrm{C}^{2} \mathrm{~m}^{2}$ & $8718 \pm 50$ \\
$\vec{\mu}_{\mathrm{a}} \Delta \mathrm{e} \vec{\mu} / 10^{-60} \mathrm{C}^{2} \mathrm{~m}^{2}$ & $4160 \pm 160$ \\
$\left(m_{\mathrm{e}} \vec{\mu}_{\mathrm{a}}\right)\left(m_{\mathrm{e}} \Delta^{\mathrm{e}} \vec{\mu}\right) / 10^{-60} \mathrm{C}^{2} \mathrm{~m}^{2}$ & $4160 \pm 160$ \\
$\mu_{\mathrm{a}} / 10^{-30} \mathrm{Cm}$ & $66 \pm 0.2$ \\
$\Delta^{\mathrm{e}} \mu / 10^{-30} \mathrm{Cm}$ & $63 \pm 2.5$ \\
$\mu_{\mathrm{g}}^{\mathrm{FC}} / 10^{-30} \mathrm{Cm}$ & $(3 \pm 2.7)$ \\
\hline
\end{tabular}

This is a very good hint that there is $\boldsymbol{m}_{\mathrm{e}}\left\|\vec{\mu}_{\mathrm{a}}\right\| \Delta \mathrm{e}^{\mathrm{\mu}}$. Then the dipole moments given in Table 2, too, can be evaluated.

\section{III.3. Results of Electrooptical Absorption Measurements}

To all knowledge the first absorption band of DMABN starting around $31 \cdot 10^{5} \mathrm{~m}^{-1}$ is a superposition of a strong transition to a singlet excited electronic state ${ }^{1} \mathrm{~A} *$ and a transition to a ${ }^{1} \mathrm{~B} *$ state that is very close to the ${ }^{1} \mathrm{~A}^{*}$ state, if $\mathrm{C}_{2}$ symmetry is assumed. EOAM clearly shows this superposition of transitions at the longwavelength tail of the absorption in $\mathrm{n}$-heptane and in dioxane. Thus EOEM in this spectral range cannot be utilized. On the other hand, from measurements over the main part of the first broad absorption band, which corresponds to the nearly unperturbed $A^{*} \leftarrow$ A transition, the terms $E^{\text {a }}$ to $I^{\text {a }}$ are determined without complications. The results are listed up in Table 3. All errors are single standard deviations from a regression analysis.

$F^{\text {a }}$ is found to be a little bit larger than $G^{\mathrm{a}}$. This might be due to experimental errors, as only single standard deviations are given, or it might be due to the neglect of minor polarizability terms, as discussed in Chapter VI.

\section{III.4. Determination of Dipole Moments from EOAM}

Taking the appropriate values of Table 3 , as is indicated in the last row of Table 4, and using (6) to (10), the values of Table 4 are found for some dipole moments of DMABN.

Table 4 shows that the moment $\mu_{\mathrm{g}}$ as determined by EOAM in dioxane is found to be in good agreement with the values reported in the literature [36-39]. The value used here for $\mu_{\mathrm{g}}$ was taken

Table 3. Results of EOAM on the $A * \leftarrow A$ transition of DMABN in dioxane and heptane solutions at $298 \mathrm{~K} . \delta \tilde{v}_{\mathrm{a}}$ is the spectral bandwidth used with EOAM.

\begin{tabular}{|c|c|c|}
\hline Solvent & Dioxane & Heptane \\
\hline$E^{\mathrm{a}} / 10^{-20} \mathrm{~V}^{-2} \mathrm{~m}^{2}$ & $10300 \pm 100$ & $8420 \pm 50$ \\
\hline 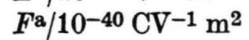 & $2100 \pm 100$ & $1240 \pm 30$ \\
\hline$G^{\mathrm{a} / 1} / 0^{-40} \mathrm{CV}^{-1} \mathrm{~m}^{2}$ & $1700 \pm 50$ & $1140 \pm 30$ \\
\hline 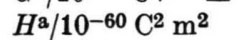 & & $350 \pm 120$ \\
\hline$I^{\mathrm{a} / 10^{-60} \mathrm{C}^{2} \mathrm{~m}^{2}}$ & & $450 \pm 120$ \\
\hline$\delta \tilde{v}_{\mathrm{a}} / 10^{5} \mathrm{~m}^{-1}$ & 0.05 & $0 . \overline{04}$ \\
\hline
\end{tabular}


Table 4. Some dipole moments of DMABN.

\begin{tabular}{lcll}
\hline Solvent & Dioxane & Heptane & $\begin{array}{l}\text { taken } \\
\text { from: }\end{array}$ \\
\hline$\mu_{\mathrm{g}} / 10^{-30} \mathrm{Cm}$ & $29.5 \pm 0.5$ & $26.7 \pm 0.1$ & $E^{\mathrm{a}}$ \\
$\Delta^{\mathrm{a}} \mu / 10^{-30} \mathrm{Cm}$ & $29.3 \pm 1.9$ & $19.1 \pm 0.6$ & $E^{\mathrm{a}}, F^{\mathrm{a}}$ \\
$\Delta^{\mathrm{a}} \mu / 10^{-30} \mathrm{Cm}$ & & $20 \pm 3$ & $H^{\mathrm{a}}, I^{\mathrm{a}}$ \\
$\mu_{\mathrm{a}}^{\mathrm{FC}} / 10^{-30} \mathrm{Cm}$ & $(58.8 \pm 1.4)$ & $45.8 \pm 0.5$ & $E^{\mathrm{a}}, F^{\mathrm{a}}$ \\
$\mu_{\mathrm{g}} / 10^{-30} \mathrm{Cm}$ & $30 \pm 4$ & & diel.* \\
\hline
\end{tabular}

* $\mu_{\mathrm{g}}$ has been determined by dielectric investigations.

from [37] where the same model has been used for the description of the effective field in a solution.

Note that $\mu_{\mathrm{a}}^{\mathrm{FC}}$ of the $\mathrm{A}^{*}$ state is found to be about $25 \%$ larger in dioxane than in heptane. $\mu_{\mathrm{a}}$ from a-fluorescence in dioxane is still larger than $\mu_{\mathrm{a}}^{\mathrm{FC}}$ in this state.

\section{Discussion of the Results from Electrooptical Studies on DMABN}

\section{IV.1. Discussion assuming $f \alpha \ll 1$}

With the assumption that all terms $f \alpha$ are negligible compared to $1,(20)$ and (21) are valid. Then with $f_{\mathrm{e}}=1.2$ the dipole moments of the free molecule given in Table 5 are calculated from the dipole moments in Tables 2 and 4.

Under these assumptions the difference found for $\mu_{\mathrm{a}}^{\mathrm{OFC}}$ in heptane and dioxane for the $\mathrm{A}^{*}$ state can only be understood if different ground state conformations exist in dioxane and heptane. If the TICT model is taken into account [7, 12], a conformer more twisted in the ground state in dioxane than in heptane would be in agreement with the experimental results.

The even more polar equilibrium state with $\mu_{\mathrm{a}}=$ $55 \cdot 10^{-30} \mathrm{Cm}$ also fits well to this model, as after excitation a further twist of the dimethylamino

Table 5. Dipole moments of free DMABN determined with the assumption that reaction field induced moments are negligible.

\begin{tabular}{lcll}
\hline & $\begin{array}{l}\text { From a- } \\
\text { fluorescence }\end{array}$ & from A* $\leftarrow$ A absorption \\
\hline Solvent & Dioxane & Dioxane & Heptane \\
$\mu_{\mathrm{a}}^{0} / 10^{-30} \mathrm{Cm}$ & $55 \pm 0.2$ & & \\
$\mu_{\mathrm{g}}^{0 \mathrm{FC}} / 10^{-30} \mathrm{Cm}$ & $2.5 \pm 2.3$ & & \\
$\mu_{\mathrm{a}}^{0 \mathrm{FC}} / 10^{-30} \mathrm{Cm}$ & & $49.0 \pm 1.2$ & $39.2 \pm 0.2$ \\
$\mu_{\mathrm{g}}^{0} / 10^{-30} \mathrm{Cm}$ & & $24.6 \pm 0.4$ & $22.3 \pm 0.1$ \\
\hline
\end{tabular}

group according to the TICT model might occur. But the very small FC-ground state dipole moment cannot be understood even in the TICT theory. This is because in that model $\mu_{\mathrm{g}}^{\mathrm{FC}}$ should have a value similar to that of benzonitrile $\left(\mu_{\mathrm{g}}^{0} \approx 12\right.$ to $\left.15 \cdot 10^{-30} \mathrm{Cm}\right)$. So the whole set of dipole moments given in Table 5 cannot be understood consistently if $f \alpha$ is assumed to be negligible compared to 1 . On the other hand all the results in Table 5 can be understood, if reaction field induced moments are taken into account, which is shown in the next section.

IV.2. Discussion Assuming that the Permanent Dipole Moment of DMABN in its $A^{*} F C$-state and in its Ground State is not Solvent Dependent

Here and in the following the left superscripts D and $\mathrm{H}$ label dioxane and heptane as solvents, respectively.

It is assumed that the permanent dipole moment and the polarizability of the ground state and the excited FC state are independent from the solvent, that means

$$
\begin{aligned}
{ }^{\mathrm{H}} \mu_{\mathrm{g}}^{0} & ={ }^{\mathrm{D}} \mu_{\mathrm{g}}^{0}, & \mathrm{H}_{\alpha_{\mathrm{g}}^{0}} & =\mathrm{D}_{\alpha_{\mathrm{g}}^{0},} \\
{ }^{\mathrm{H}} \mu_{\mathrm{a}}^{0 \mathrm{FC}} & ={ }^{\mathrm{D}} \mu_{\mathrm{a}}^{0 \mathrm{FC}}, & \mathrm{H}_{\alpha_{\mathrm{a}}^{0 \mathrm{FC}}} & =\mathrm{D}_{\alpha_{\mathrm{a}}^{0 \mathrm{FC}}} .
\end{aligned}
$$

Because of the symmetry axis (z-axis) all $(1-f \alpha)$ like terms must be considered as $\left(1-f \alpha_{z z}^{0}\right)$ terms, furtheron.

From (13) a term $S_{1}$ may be defined:

$$
S_{1}=\frac{\mathrm{D}^{\mathrm{a}} \mu}{\mathrm{D}_{\mu \mathrm{a}}^{\mathrm{FC}}-{ }^{\mathrm{D}} \mu_{\mathrm{g}}}=\frac{1-\mathrm{D}^{\mathrm{D}} \alpha_{\mathrm{a} z z}^{0 \mathrm{FC}}}{1-\mathrm{D}^{\prime} \alpha_{\mathrm{a} z z}^{0 \mathrm{FC}}} \frac{1-\mathrm{D}^{\prime} \alpha_{\mathrm{g} z z}^{0}}{1-\mathrm{D}^{\mathrm{D}} \alpha_{\mathrm{g} z z}^{0}} \text {. }
$$

Using $\mathrm{D}^{\prime}=\mathrm{H}_{f},(23)$ can be rewritten to give

$$
S_{1}=\frac{{ }^{\mathrm{H}} \mu_{\mathrm{a}}^{\mathrm{FC}}}{{ }_{\mathrm{H}}^{\mathrm{C}} \mu_{\mathrm{g}}}-\frac{\mathrm{D}^{\mathrm{a}} \mu}{\mathrm{D} \mu_{\mathrm{g}}} .
$$

Taking the values of these dipole moments from Table 4, $S_{1}$ can be calculated:

$$
S_{1}=0.725 \pm 0.012 \text {. }
$$

From ${ }^{\mathrm{D}} \mu_{\mathrm{g}}$ and ${ }^{\mathrm{H}} \mu_{\mathrm{g}}$ a term $S_{2}$ can be defined:

$$
S_{2}=\frac{{ }^{\mathrm{D}} \mu_{\mathrm{g}}}{{ }^{\mathrm{H}} \mu_{\mathrm{g}}}=\frac{1-{ }^{\mathrm{H}} f \alpha_{\mathrm{g} z z}^{0}}{1-{ }^{\mathrm{D}} f \alpha_{\mathrm{g} z z}^{0}} .
$$

With the values from Table $4, S_{2}$ is found to be

$$
S_{2}=1.105 \pm 0.025 \text {. }
$$


Combining (23) and (25), a term $S_{3}$ may be defined:

$$
S_{3}=\frac{1-{ }^{\mathrm{H}} f \alpha_{\mathrm{azz}}^{0 \mathrm{FC}}}{1-{ }^{\mathrm{D}} f \alpha_{\mathrm{azz}}^{0 \mathrm{FC}}}
$$

With the values for $S_{1}$ and $S_{2}$ determined above, $S_{3}$ is found to be $S_{3}=1.52 \pm 0.06$.

Note that $S_{1}, S_{2}$ and $S_{3}$ have been calculated with dipole moments determined only by one method, namely EOAM. So calibration errors etc. do not influence these results.

With these values for $S_{2}$ and $S_{3}$ at first $\alpha_{\mathrm{gzz}}^{0} / 2 \pi \varepsilon_{0} a^{3}$ and $\alpha_{\mathrm{azz}}^{0 \mathrm{FC}} / 2 \pi \varepsilon_{0} a^{3}$ and then terms $\left(1-f \alpha_{z z}^{0}\right)$ and the dipole moments of the free molecule can be calculated, using ${ }^{\mathrm{D}_{\varepsilon}}=6$ and $\mathrm{H}_{\varepsilon}=2$ for the description of the reaction field. ${ }^{D} \varepsilon=6$ as an effective dielectric constant of dioxane is used in the following, because in all solvatochromism measurements dioxane behaves as a solvent with $\mathrm{D}_{\varepsilon} \approx 6$. The results are shown in Table 6 and 7 together with the ratio $\alpha_{\mathrm{azz}}^{0 \mathrm{FC}}: \alpha_{\mathrm{g} z z}^{0}$.

With the values of Tables 4 and 6 and with $f_{\mathrm{e}}=1.2$, the dipole moments in Table 7 result, using (11), (13) and (16).

The results in Table 7 show:

$\mu_{\mathrm{g}}^{0}$ determined from EOAM in dioxane and heptane and from dielectric investigations agree very well. The excited A* FC-state has a slightly larger dipole moment than the ground state. Clearly from the assumptions, $\mu_{\mathrm{a}}^{\mathrm{OFC}}$ in dioxane and heptane and

\begin{tabular}{ll}
\hline$\alpha_{\mathrm{gzz}}^{0} / 2 \pi \varepsilon_{0} a^{3}$ & $0.465 \pm 0.1$ \\
$\alpha_{\mathrm{azz}}^{0 \mathrm{FC}} / 2 \pi \varepsilon_{0} a^{3}$ & $1.35 \pm 0.08$ \\
$\alpha_{\mathrm{azz}}^{0 \mathrm{FC}}: \alpha_{\mathrm{gzz}}^{0}$ & $2.9 \pm 0.7$ \\
$1-{ }_{\mathrm{H} f}^{0 \mathrm{FC}}$ & $0.730 \pm 0.015$ \\
$1-\mathrm{D} f \alpha_{\mathrm{a} z}^{0 \mathrm{FC}}$ & $0.480 \pm 0.03$ \\
$1-\mathrm{H} f \alpha_{\mathrm{gzz}}^{0}$ & $0.907 \pm 0.02$ \\
$1-\mathrm{D} f \alpha_{\mathrm{g} z z}^{0}$ & $0.821 \pm 0.034$ \\
\hline
\end{tabular}

Table 6. $\alpha_{\mathrm{gzz}}^{0} / 2 \pi \varepsilon_{0} a^{3}$, $\alpha_{\mathrm{azz}}^{0 \mathrm{FC}} / 2 \pi \varepsilon_{0} a^{3}, \alpha_{\mathrm{azz}}^{0 \mathrm{FC}}: \alpha_{\mathrm{g} z z}^{0}$ and $\left(1-f \alpha_{z z}^{0}\right)$ type terms, using ${ }^{D_{\varepsilon}}=6$.

Table 7. Dipole moments of the free molecule DMABN, as determined from EOAM.

Taken from:

\begin{tabular}{lll}
\hline$\mu_{\mathrm{g}}^{0} / 10^{-30} \mathrm{Cm}$ & $20.5 \pm 0.9$ & dielectric investigations \\
$\mu_{\mathrm{g}}^{0} / 10^{-30} \mathrm{Cm}$ & $20.2 \pm 0.6$ & $\mu_{\mathrm{g}}$, dioxane \\
$\mu_{\mathrm{g}}^{0} / 10^{-30} \mathrm{Cm}$ & $20.2 \pm 1.3$ & $\mu_{\mathrm{g}}$, heptane \\
$\mu_{\mathrm{a}}^{0 \mathrm{FC}} / 10^{-30} \mathrm{Cm}$ & $27.9 \pm 6$ & $\mu_{\mathrm{g}}, \Delta^{\mathrm{a}} \mu$, heptane \\
$\mu_{\mathrm{a}}^{0 \mathrm{FC}} / 10^{-30} \mathrm{Cm}$ & $27.9 \pm 1$ & $\mu_{\mathrm{g}}, \Delta^{\mathrm{a}} \mu$, dioxane \\
\hline
\end{tabular}

$\mu_{\mathrm{g}}^{0}$ in these solvents must be found identical within their error margins.

\section{IV.3. Discussion on the Permanent Dipole Moment of the Excited $A^{*}$-State, Emitting a-Fluorescence}

Table 5 shows that with the assumptions $f \alpha \ll 1$ an FC ground state dipole moment $\mu_{\mathrm{g}}^{0 \mathrm{FC}}$ is determined from the experimental values for $\mu_{\mathrm{a}}$ and $\Delta \mathrm{e} \mu$ that seems to be unacceptably small, as discussed in Chapter IV.1.

On the other hand in Chapter IV.2 it has been shown that the solvent dependence of $\mu_{\mathrm{g}}$ and $\Delta^{\mathrm{a}} \mu$ can be fully understood, if $(1-f \alpha)$ type terms are taken into account. So one could ascribe the discrepancy between $\mu_{\mathrm{a}}$ and $\Delta \mathrm{e} \mu$ at least to a great deal to the neglect of these terms, too.

Two limiting cases may be considered:

case a) $\mu_{\mathrm{g}}^{0 \mathrm{FC}}$ and $\alpha_{\mathrm{g}}^{0 \mathrm{FC}}$ of the species emitting a-fluorescence in dioxane are the same as $\mu_{\mathrm{g}}^{0}$ and $\alpha_{\mathrm{g}}^{0}$ of the molecule in its equilibrium ground state. Then it follows

$$
\mathrm{D}_{\mathrm{g}}^{\mathrm{FC}}=\mathrm{D}_{\mathrm{g}_{\mathrm{g}}}=(29.5 \pm 0.5) \cdot 10^{-30} \mathrm{Cm} ;
$$

case b) $\mu_{\mathrm{g}}^{0 \mathrm{FC}}$ and $\alpha_{\mathrm{g}}^{0 \mathrm{FC}}$ of the emitting species in dioxane are the same as those of the TICT ground state, the dipole moment of which might be very roughly taken as that of benzonitrile, which gives

$$
{ }^{\mathrm{D}} \mu_{\mathrm{g}}^{\mathrm{FC}}=\mathrm{D}_{\mu_{\mathrm{g}, \mathrm{TICT}}}=(20 \pm 3) \cdot 10^{-30} \mathrm{Cm}[40] .
$$

These two limiting cases are considered parallely, furtheron.

From (14) a term $S_{1}{ }^{\prime}$ can be defined:

$$
S_{1}{ }^{\prime}=\frac{\mathrm{D}^{\mathrm{e}} \mu}{{ }^{\mathrm{D}} \mu_{\mathrm{a}}-{ }^{\mathrm{D}} \mu_{\mathrm{g}}^{\mathrm{FC}}}=\frac{1-\mathrm{D}^{\prime} \alpha_{\mathrm{a} z z}^{0}}{1-\mathrm{D}^{\mathrm{D}} \alpha_{\mathrm{a} z z}^{0}} \cdot \frac{1-{ }^{\mathrm{D}} f \alpha_{\mathrm{ggz}}^{0 \mathrm{FC}}}{1-{ }^{\mathrm{D}} f^{\prime} \alpha_{\mathrm{g} z z}^{0 \mathrm{FC}}} .
$$

With the values of Table 2 and those discussed above, $S_{1}{ }^{\prime}$ can be calculated:

$$
\begin{aligned}
\left.S_{1}{ }^{\prime}=1.726 \pm 0.1 \quad \text { case } a\right), \\
1.370 \pm 0.16 \text { case } b) .
\end{aligned}
$$

The term $\left(1-\mathrm{D}^{\prime} \alpha_{\mathrm{g} z z}^{0 \mathrm{FC}}\right) /\left(1-{ }^{\mathrm{D}} f \alpha_{\mathrm{gzz}}^{0 \mathrm{FC}}\right)$ can be taken equal to $S_{2}$ of (25) in both cases in good approximation, because even if there are different values for $f \alpha_{\mathrm{gzz}}^{0 \mathrm{FC}}$ in postulated FC ground states with TICT conformation, or with planar FC ground state conformation, or with equilibrium ground state conformation, the influence of such differences on $S_{2}$ 
Table 8. The dipole moment $\mu_{\mathrm{a}}^{0}$ of the $\mathrm{A}^{*}$ state emitting a-fluorescence.

\begin{tabular}{lcc}
\hline & Case a) & Case b) \\
\hline$\alpha_{\mathrm{a} z z}^{0} / 2 \pi \varepsilon_{0} a^{3}$ & $1.70 \pm 0.1$ & $1.34 \pm 0.2$ \\
$1-\mathrm{D} f \alpha_{\mathrm{a} z z}^{0}$ & $0.347 \pm 0.036$ & $0.483 \pm 0.08$ \\
$\mu_{\mathrm{a}}^{0} / 10^{-30} \mathrm{Cm}$ & $19.1 \pm 1.9$ & $26.6 \pm 4.4$ \\
\hline
\end{tabular}

is small, as $S_{2}$ itself is nearby 1 . So the erorr introduced by this uncertainty in $f \alpha_{\mathrm{gzz}}^{\mathrm{OFC}}$ clearly is small.

With $S_{2}$ from Chapter IV.2 and $S_{1}{ }^{\prime}$ taken from above, $S_{3}{ }^{\prime}$ may be calculated:

$S_{3}^{\prime}=\frac{1-{ }^{\mathrm{D}} f^{\prime} \alpha_{\mathrm{azz}}^{0}}{1-{ }^{\mathrm{D}} f \alpha_{\mathrm{azz}}^{0}}=\begin{array}{ll}1.907 \pm 0.016 & \text { case a) } \\ 1.514 \pm 0.02 & \text { case b) }\end{array}$

This value for $S_{3}{ }^{\prime}$ may be compared to the value found for $S_{3}$ Section IV.2. Although the errors of $S_{3}{ }^{\prime}$ are pretty high, $S_{3}{ }^{\prime}$ resembles $S_{3}$ very well, especially in case b).

With $S_{3}{ }^{\prime}$ the values of $\alpha_{\mathrm{azz}}^{0} / 2 \pi \varepsilon_{0} a^{3}$ and then $\left(1-\mathrm{D}_{f} \alpha_{\mathrm{a} z z}^{0}\right)$ and $\mu_{\mathrm{a}}^{0}$ can be calculated. Using $f_{\mathrm{e}}=1.2$ one gets the results shown in Table 8.

The dipole moment $\mu_{\mathrm{a}}$ found for either case a) or b) is in between $\mu_{\mathrm{g}}$ and $\mu_{\mathrm{a}}^{0 \mathrm{FC}}$, as can be seen by comparison with the results in Table 7 , and $\alpha_{\mathrm{azz}}^{0}$ is nearly equal to $\alpha_{\mathrm{a}}^{\mathbf{F C}}$ within the errors, as may be seen by comparison with the results in Table 6 .

So from these results it may be deduced that if there is a TICT formation after excitation in dioxane to give a-fluorescence, this TICT state has a dipole moment not much larger than the ground state and very similar to that of the A* FC excited state, and a polarizability also very similar to that of the $A^{*}$ FC excited state.

\section{The Onsager Cavity Radius a}

\section{V.1. The Solvent Dependent Spectral Shift of the $a$-Fluorescence and the Determination of the Onsager Cavity Radius a}

Lippert [1] has shown the solvatochromism of the a-fluorescence of DMABN. These results seem to oppose the results reported here. But if the terms $(1-f \alpha)$ differ markedly from 1, Lippert's [41] or Mataga's [42] formulae describing solvent shifts are no more valid. Instead, the more elaborated formulae of Liptay [43] must be used. In good approxi- mation this formula is written as

$$
\begin{aligned}
h c \tilde{\nu}_{\mathrm{e}}= & \text { const }-\frac{1}{2 \pi \varepsilon_{0}} \cdot \frac{1}{a^{3}} F(g) \\
& \cdot\left\{\vec{\mu}_{\mathrm{a}}^{0}\left(\vec{\mu}_{\mathrm{a}}^{0}-\vec{\mu}_{\mathrm{g}}^{0 \mathrm{FC}}\right)+\left(1-f^{\prime} \alpha_{\mathrm{g}}^{0 \mathrm{FC}}\right)^{-1}\right. \\
& \cdot\left(1-f \alpha_{\mathrm{a}}^{0}\right)^{-1} \vec{\mu}_{\mathrm{a}}^{0} \cdot\left[\frac{1}{2} f\left(\alpha_{\mathrm{a}}^{0}-\alpha_{\mathrm{g}}^{0 \mathrm{FC}}\right)\right. \\
& \cdot\left(1-f^{\prime} \alpha_{\mathrm{a}}^{0}\right) \vec{\mu}_{\mathrm{a}}^{0}-f^{\prime}\left(\alpha_{\mathrm{a}}^{0}-\alpha_{\mathrm{g}}^{0 \mathrm{FC}}\right) \\
& \left.\left.\cdot\left(1-f \alpha_{\mathrm{a}}^{0}\right)\left(\vec{\mu}_{\mathrm{a}}^{0}-\vec{\mu}_{\mathrm{g}}^{0 \mathrm{FC}}\right)\right]\right\}
\end{aligned}
$$

where

$$
F(g)=\left(g^{-1}-\frac{1}{2 \pi \varepsilon_{0}} \frac{\alpha_{\mathrm{a} z z}^{0}}{a^{3}}\right)^{-1}
$$

with

$$
g=(\varepsilon-1) /(2 \varepsilon+1) .
$$

In order to get a simple but sufficiently accurate plot of $\tilde{\nu}_{\mathrm{e}}$ against $F(g)$, the total term in braces is calculated, using the results from Tables 5 and 6 and estimating the solvent dependent terms

$$
\left(1-f \alpha_{\mathrm{azz}}^{0}\right) \text { and }\left(1-f \alpha_{\mathrm{gzz}}^{0 \mathrm{FC}}\right)
$$

in the minor part of the sum in braces to be $\mathbf{0 . 5 5}$ \pm 0.2 and $0.85 \pm 0.06$, respectively.

Then using Lippert's data [1], from a plot in Fig. 1 according to $(28), a^{3}$ is found to be $(49.5 \pm 20)$ $\cdot 10^{-30} \mathrm{~m}^{3}$, and from this $a=(3.7 \pm 0.5) \cdot 10^{-10} \mathrm{~m}$.

This is a relatively small value, but it seems to be plausible as a mean value over the three molecular axis.

So the results from solvent shift measurements supply consistently the results from electrooptical investigations.

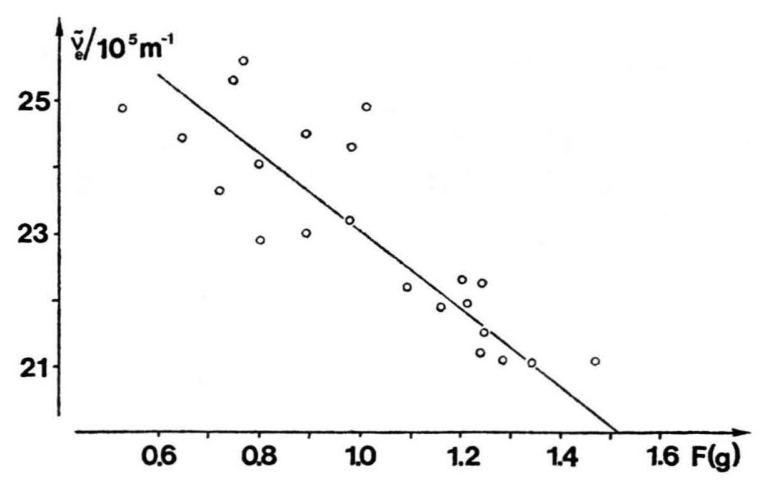

Fig. 1. Plot of $\tilde{\nu}_{\mathrm{e}}$ against $F(g)$. 


\section{V.2. Determination of the Onsager Radius by use of $\alpha_{\mathrm{g}}^{0}$}

From refraction measurements [37] tr $\alpha_{\mathrm{g}}^{0}$ is known

$$
\operatorname{tr} \alpha_{\mathrm{g}}^{0}=(64.5 \pm 3) \cdot 10^{-40} \mathrm{CV}^{-1} \mathrm{~m}^{2} .
$$

From group polarizabilities together with this value, $\alpha_{\mathrm{g} z z}^{0}$ may be estimated to be

$$
\alpha_{\mathrm{g} z z}^{0}=(27 \pm 4) \cdot 10^{-40} \mathrm{CV}^{-1} \mathrm{~m}^{2} .
$$

With this value $a^{3}$ can be estimated using $\alpha_{\mathrm{g} z z}^{0} /$ $2 \pi \varepsilon_{0} a^{3}$ from Table 6 :

$$
a^{3}=(104 \pm 40) \cdot 10^{-30} \mathrm{~m}^{3}
$$

or

$$
a=(4.7 \pm 0.7) \cdot 10^{-10} \mathrm{~m} .
$$

This value is much larger than that determined from solvent shift measurements, but overlaps within the errors.

Although the value for $a^{3}$ determined from solvent shift measurements fits better to the molecular dimensions that might be estimated as

$$
\begin{aligned}
a^{3} & =(5 \times 3.5 \times 2.5) \cdot 10^{-30} \mathrm{~m}^{3} \\
& =44 \cdot 10^{-30} \mathrm{~m}^{3},
\end{aligned}
$$

this is not an argument to favour that value, if $a^{3}$ is considered to be a parameter which comprises a lot of effects.

Thus these results also must be seen as consistent with those from electrooptical investigations.

\section{Critical Check on the Neglectability of Explicit Polarizabilities}

In Chapter II explicit polarizability terms [31] have been neglected as minor terms. Now, with the data calculated on the basis of this simplification, the explicit polarizability terms $\frac{1}{2} \operatorname{tr} \Delta^{\mathrm{a}} \alpha$ and $\frac{1}{2} \operatorname{tr} \Delta^{\mathrm{e}} \alpha$ may be calculated and can be compared to the experimental values of $F^{\mathrm{a}}$ and $F^{\mathrm{e}}$ according to Eqs. (100) and (110) from Ref. [31]. With the definition of $\Delta^{\mathrm{a}} \boldsymbol{\alpha}$ and $\Delta^{\mathrm{e}} \boldsymbol{\alpha}$ from Eqs. (37) and (40) of Ref. [31] and with the values from Tables 6 and 8 and from Section IV.4 $\frac{1}{2} \operatorname{tr} \Delta^{\mathrm{a}} \alpha$ and $\frac{1}{2} \operatorname{tr} \Delta^{\mathrm{e}} \boldsymbol{\alpha}$ are found to be

$$
\begin{aligned}
\frac{1}{2} \operatorname{tr} \Delta^{\mathrm{a}} \alpha= & (133 \pm 55) \cdot 10^{-40} \mathrm{CV}^{-1} \mathrm{~m}^{2} \\
& \text { in heptane } \\
= & (161 \pm 100) \cdot 10^{-40} \mathrm{CV}^{-1} \mathrm{~m}^{2} \\
& \text { in dioxane }, \\
\frac{1}{2} \operatorname{tr} \Delta^{\mathrm{e}} \alpha= & (468 \pm 300) \cdot 10^{-40} \mathrm{CV}^{-1} \mathrm{~m}^{2} \\
& \text { in dioxane, case b). }
\end{aligned}
$$

Comparing $\frac{1}{2} \operatorname{tr} \Delta^{\mathrm{e}} \boldsymbol{\alpha}$ with $F^{\mathrm{e}}$ in Table 1 immediately shows that the results from EOEM reported are by no way changed if $\frac{1}{2} \operatorname{tr} \Delta^{\mathrm{e}} \alpha$ is taken into account. But a comparison of $\frac{1}{2} \operatorname{tr} \Delta^{\mathrm{a}} \alpha$ with $F^{\mathrm{a}}$ in Table 3 shows that $\frac{1}{2} \operatorname{tr} \Delta^{\mathrm{a}} \alpha$ amounts up to 10 to $15 \%$ of $F^{\mathrm{a}}$. A brief recalculation of the results of EOAM reported here shows that the results are not changed to a substantial amount, as $S_{1}$ to $S_{3}$ are not changed at all by taking into account $\frac{1}{2} \operatorname{tr} \Delta^{\mathrm{a}} \alpha$. As the influence of polarizabilities on $G^{\mathrm{a}}$ and $G^{\mathrm{e}}$ (cf. Ref. [31]) is similar, it may be seen that the results reported here on polarizabilities are correct. The dipole moment $\mu_{\mathrm{a}}^{\mathrm{OFC}}$ as reported in Table 7 is changed from $27.9 \cdot 10^{-30} \mathrm{Cm}$ to $26.7 \cdot 10^{-30} \mathrm{Cm}$ taking into account $\frac{1}{2} \operatorname{tr} \Delta^{\mathrm{a}} \boldsymbol{\alpha}$, and this clearly is within the errors. So a recurrence cannot improve the results, or even change the interpretation of the results from EOAM and EOEM on DMABN.

\section{Concluding Remarks}

It has been shown that the results from EOEM could only be understood taking into account terms like $(1-f \alpha)^{-1}$. Then EOEM give a permanent dipole moment $\mu_{\mathrm{a}}^{0}$ for the excited state emitting the a-fluorescence that is in between 19 and $27 \cdot 10^{-30} \mathrm{Cm}$. $\mu_{\mathrm{a}}^{0 \mathrm{FC}}$ of the $\mathrm{FC}$ excited $\mathrm{A}^{*}$ state is determined from EOAM to be around $28 \cdot 10^{-30} \mathrm{Cm}$. This means that the permanent dipole moment increases with excitation but does not increase further with the following solvent or intramolecular relaxation.

So the results presented here do neither interfere with the TICT model nor with the level crossing model in their essential points. But in the case of the TICT model, the postulated twisted rotamer does not show a nearly full charge transfer, and in the case of the level crossing model, the level crossing is to an essential amount due to polarizabilities.

In order to elucidate the part of polarizabilities in the total effective dipole moments in solvents further, electrooptical investigations on sterically hindered molecules related to DMABN are under way. Such investigations also suggest themselves because electrooptical investigations on ADMA [21] and on a class of merocyanine dyes show strong evidence that polarizabilities cannot be neglected.

I thank Prof. Dr. W. Liptay for many stimulating discussions. Financial support of the Deutsche Forschungsgemeinschaft and the Fonds der Chemischen Industrie is gratefully acknowledged. 
[1] E. Lippert, W. Lüder, and H. Boos, in: Adv. in Molec. Spectroscopy, ed. A. Mangini, Pergamon Press, London 1962, p. 443.

[2] O.S. Khalil, R. H. Hofeldt, and S. P. McGlynn, Chem. Phys. Lett. 17, 479 (1972).

[3] N. Nakashima and N. Mataga, Bull. Chem. Soc. 46, 3016 (1973).

[4] E. M. Kosower and H. Doduik, J. Amer. Chem. Soc. 98, 924 (1976).

[5] E. A. Chandross, in: "The Exciplex", eds. Gordon and Ware, Academic Press, New York 1975, p. 187.

[6] R. Visser and C. A. G. O. Varma, J. C. S. Faraday II 76, 453 (1980).

[7] K. Rotkiewicz, K. H. Grellmann, and Z. R. Grabowski, Chem. Phys. Lett. 19, 315 (1973). Erratum, Chem. Phys. Lett. 21, 212 (1973).

[8] K. Rotkiewicz, Z. R. Grabowski, and J. Jasny, Chem. Phys. Lett. 34, 55 (1975).

[9] K. Rotkiewicz, Z. R. Grabowski, A. Krówczyński, and W. Kühnle, J. Luminescence 12/13, 877 (1976).

[10] Z. R. Grabowski, K. Rotkiewicz, W. Rubaszewska, and E. Kirkor-Kamińska, Acta Physica Polon. A54, 767 (1978).

[11] Z. R. Grabowski, K. Rotkiewicz, A. Siemiarczuk, D. J. Cowley, and W. Baumann, Nouveau J. Chim. 3, 443 (1979).

[12] Z. R. Grabowski, K. Rotkiewicz, and A. Siemiarczuk, J. Luminescence 18/19, 420 (1979).

[13] J. Lipiński, H. Chojnacki, Z. R. Grabowski, and K. Rotkiewicz, Chem. Phys. Lett. 70, 449 (1980).

[14] O. S. Khalil, J. L. Meeks, and S. P. McGlynn, Chem. Phys. Lett. 39, 457 (1976).

[15] D. J. Cowley and A. H. Peoples, J. Chem. Soc., Chem. Comm. 1977, 352.

[16] W. Rettig and V. Bonacić-Koutecký, Chem. Phys. Lett. 62, 115 (1979).

[17] F. D. Lewis and B. Holman III, J. Phys. Chem. 84, 2326 (1980).

[18] W. Rettig, G. Wermuth, and E. Lippert, Ber. Bunsenges. Phys. Chem. 83, 692 (1979).
[19] G. Wermuth, W. Rettig, and E. Lippert, Ber. Bunsenges. Phys. Chem. 85, 64 (1981).

[20] W. Rettig and E. Lippert, J. Mol. Structure 61, 17 (1980).

[21] W. Baumann, F. Petzke, and K.-D. Loosen, Z. Naturforsch. 34 a, 1070 (1979).

[22] H. Labhart, Helv. chim. Acta 44, 457 (1961).

[23] H. Labhart, Chimia 15, 20 (1961).

[24] H. Labhart, Tetrahedron 19, Suppl. 2, 223 (1962).

[25] W. Liptay and J. Czekalla, Z. Naturforsch. 15a, 1072 (1960).

[26] W. Liptay and J. Czekalla, Ber. Bunsenges. Phys. Chem. 65, 721 (1961).

[27] W. Liptay, Z. Naturforsch. 20a, 272 (1965).

[28] W. Liptay and G. Walz, Z. Naturforsch. 26a, 2007 (1971).

[29] W. Liptay, in: Excited States, Vol. 1, p. 129, Academic Press, New York 1974.

[30] W. Liptay, Ber. Bunsenges. Phys. Chem. 80, 207 (1976).

[31] W. Baumann and H. Deckers, Ber. Bunsenges. Phys. Chem. 81, 786 (1977).

[32] L. Onsager, J. Amer. Chem. Soc. 58, 1486 (1936).

[33] Th. G. Scholte, Physica 15, 437 (1949).

[34] W. Baumann, Ber. Bunsenges. Phys. Chem. 80, 231 (1976).

[35] H. Deckers and W. Baumann, Ber. Bunsenges. Phys. Chem. 81, 795 (1977).

[36] K.-O. Meyer, Dissertation, Würzburg 1962.

[37] H. Deckers, Dissertation, Mainz 1975.

[38] E. Hertel and E. Dumont, Z. physik. Chem. B30, 139 (1935).

[39] P. P. Shorygin, M. A. Geiderikh, and T. I. Ambrush, Russ. J. Phys. Chem. 34, 157 (orig. page 335) (1960).

[40] A. L. McClellan, Tables of Experimental Dipole Moments, Vol. 1, Freeman Comp., San Francisco 1963; Vol. 2, Rahara Enterprises, El Cerrito, USA 1974.

[41] E. Lippert, Z. Elektrochem. 61, 962 (1957).

[42] N. Mataga, Y. Kaifu, and M. Koizumi, Bull. Chem. Soc. Japan 29, 465 (1956).

[43] W. Liptay, Z. Naturforsch. 20a, 1441 (1965). 